\title{
Construction And Study Of Aridity Index Based On Temperature \& Rainfall Data In Ishurdi, Pabna, Bangladesh.
}

\author{
M.A Rahman ${ }^{1}$, M.K Alam ${ }^{2}$, M.A Ali ${ }^{3}$ and M.S Islam ${ }^{4}$ \\ ${ }^{1}$ Lecturer Dept. of Applied Physics \& Electronic Engineering, Rajshahi University, Rajshahi, 6205 \\ ${ }^{2}$ Asst. Professor, Dept. of Physics, Pabna University of Science and Technology, Pabna 6600 \\ ${ }^{3}$ M.Sc. Applied Physics \& Electronic Engineering, Rajshahi University, Rajshahi, 6205 \\ ${ }^{4}$ Asst. Professor, Dept. of Physics, Government Edward College Pabna, 6600
}

\begin{abstract}
Changing patterns of aridity index have important implications on agriculture of Bangladesh. Aridity can be equates with a deficiency of rainy days and ground moisture. In this study the Aridity Index in Ishurdi Pabna from time period (1996-2011) has been computed using De Martonne (1926). Linear regression method is used to analysis the trend of Temperature \& Rainfall and also has been used for projection. A study has been carried out to assess the increases of both temperature and rainfall in the Ishurdi Pabna. The monthly De Martonne (1926) aridity index is used to evaluate the monthly aridity index and it reveals the irrigation months in the study area. The rainfall characteristic is also analyzed which is used to compute the rainfall distribution within a year. An increasing trend of precipitation concentration is also observed in the study area. These results may be a first indication of the precipitation response to global warming.
\end{abstract}

Keywords: Aridity, Precipitation, Temperature, Irrigation

\section{Introduction}

Land surface process have become a great concern in the context of global change and increased natural hazards all over the world. Through the geobiosperic process it controls the environmental, hydrological, and climatic condition of the area. Water is a limiting factor for the world's economy because of its decreasing quality and changes in distribution. With global warming, an increase in aridity is predicted for some areas in some model scenarios which estimated that drought would persist in critical agricultural regions in the Northwestern Part of Bangladesh. Agriculture is the single most and the largest producing sector of Bangladesh economy, contributing about 33\% to the national GDP and employing around $60 \%$ of the total labour force [1].The performance of this sector has an overwhelming impact on major macroeconomic objectives like employment generation, poverty alleviation, human resources development and food security. Though Bangladesh is a land of mighty rivers and heavy rainfall, irrigation plays a vital role for half of the year when water scarcity seriously handicaps farming operation. The country experienced eight droughts of severe magnitude in the years of 1973-1999 (Shahid, 2008; Shahid and Behrawan, 2008) [2] [3].Rainfall variability in space and time is one of the most relevant characteristics of the climate of Bangladesh. Climatic modelers forecast that as the world warm, the monsoon rains in Bangladesh will be increased and at the same time winter precipitation will be decreased. This will cause a cruel combination of more extreme floods and longer periods of droughts. Hydrological changes are the most significant potential impacts of global climate change in Bangladesh. Northwest part of Bangladesh is one of the most vulnerable regions of Bangladesh to climate change in respect of water resources. The impacts of more variable precipitation and extreme weather events are already felt in the region. Delayed monsoon, more variation in inter-annual rainfall, extreme temperature events such as record breaking severe hot and cold spells indicate a change of climate in the region. Decreasing rainfall in dry season with higher evapotranspiration due to temperature rise will demand higher amount of water for irrigation. At the same time the higher temperature will change the crop physiology and shorten the crop growth period. This will reduce the irrigation days. These contradictory phenomena will change the total irrigation water demand. As agriculture is the main sector of water use in northwest Bangladesh, estimation of the agricultural water demand in the changing environment is essential for long-term water resources development and planning in the area of Bangladesh. Therefore, for disaster mitigation, agriculture and water resources planning and management in the context of global climatic change it is essential to study the characteristics and trends of rainfall in Bangladesh. In the present paper, Construction and study of Aridity Index based on Temperature \& Rainfall data in Ishurdi Pabna has been analyzed from time period (1996-2011).

\subsection{Description of data}

\section{Data and Methods}

The data used in the present study are mostly secondary in nature. Data are collected from different sources including Bangladesh Bureau of Statistics (BBS), Bangladesh Meteorological Department (BMD), and 
Bangladesh Water Development Board (BWDB), Ishurdi weather station etc. Data quality control is a necessary step before analyzing their trends. A number of checks are carried out for quality controls of data such as precipitation values below $0 \mathrm{~mm}$, winter rainfall higher than $100 \mathrm{~mm}$ and dry month in monsoon. In some cases data are validated by the climate records of nearby stations.

\subsection{Procedure}

De Martonne (1926) proposed a method for calculating aridity index (AI) of an area using following equation (1)

$$
A I=\left\lceil\frac{p}{(T+10)}+\frac{12 p}{(t+10)}\right\rceil / 2
$$

Where: $\mathrm{P}$ is the mean annual precipitation in $\mathrm{mm}$,

$\mathrm{T}$ is mean annual temperature in ${ }^{\circ} \mathrm{C}$,

$\mathrm{p}$ the precipitation of the direst month in $\mathrm{mm}$,

$\mathrm{t}$ the mean temperature of the direst month in ${ }^{\circ} \mathrm{C}$

Equation 1 gives us the index value of 26.26 i.e. the moist sub-humid class according to table 1 . Fig 1 and fig 2 shows the aridity index for two different seasons for the period 1996-2011.

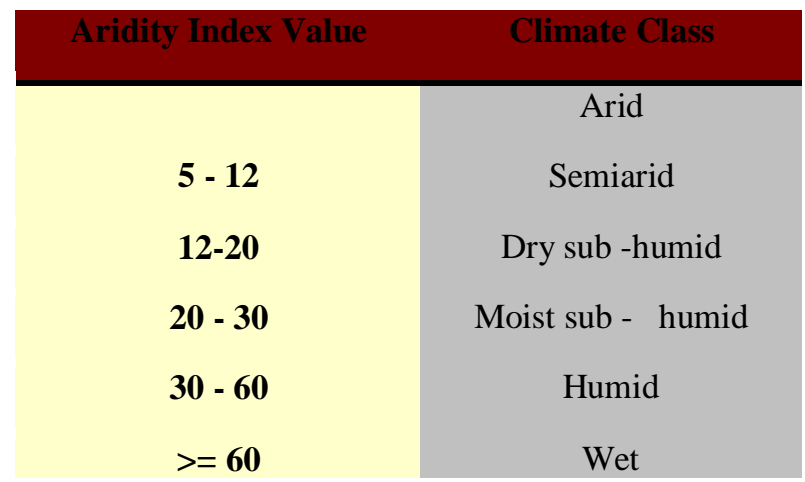

Table: 1 Climate types proposed by De Martonne (1926)

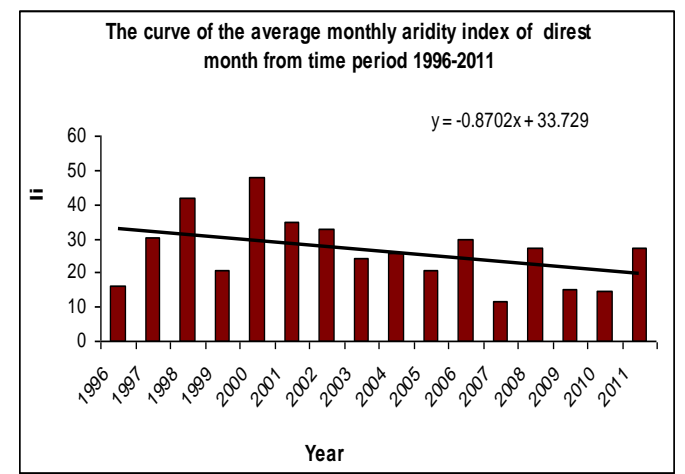

Fig.1 Trend of the average monthly aridity index of direst month (pre-monsoon) for time period (1996-2011)

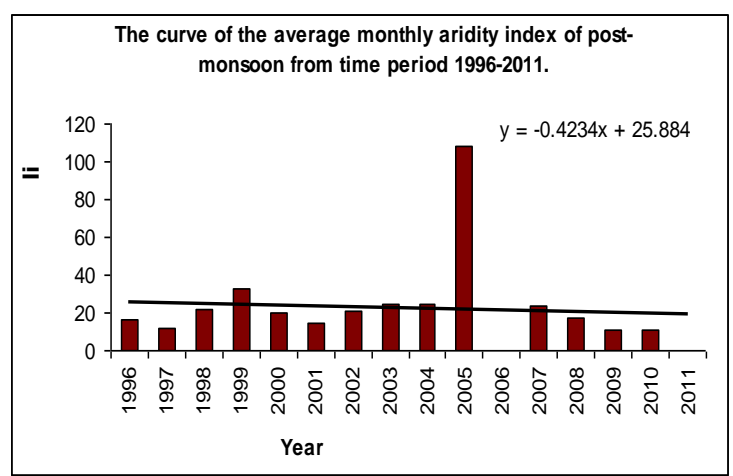

Fig. 2 Trend of the average monthly aridity index of post-monsoon period for time period (1996-2011)

\subsection{Temperature}

Trend of temperature is calculated to envisage the temporal pattern of climate in the study area. There exist numerous parametric methods, such as moving average or running mean, linear regression (Gregory, 1978; Lanzante, 1996)[4] [5] etc. and non-parametric method, such as Mann-Kendall's test, Spearman's test, etc. The Mann-Kendall trend test (Mann 1945; Kendall 1975) has been used in the present study to analyze the trends of temperature. Fig.3 shows the annual temperature for the time period 1996-2011. Bangladesh has a typical tropical monsoon climate. The summers are warm to hot and winters cool. The mean annual temperature from time period (1996-2011) of the investigated area is approximately $25.79^{\circ} \mathrm{C}$ as recorded by the station. The 
hottest month is April which maximum temperature is $35.12^{\circ} \mathrm{C}$ and the coldest month is January which temperature is $10.27^{\circ} \mathrm{C}$ in my study area.

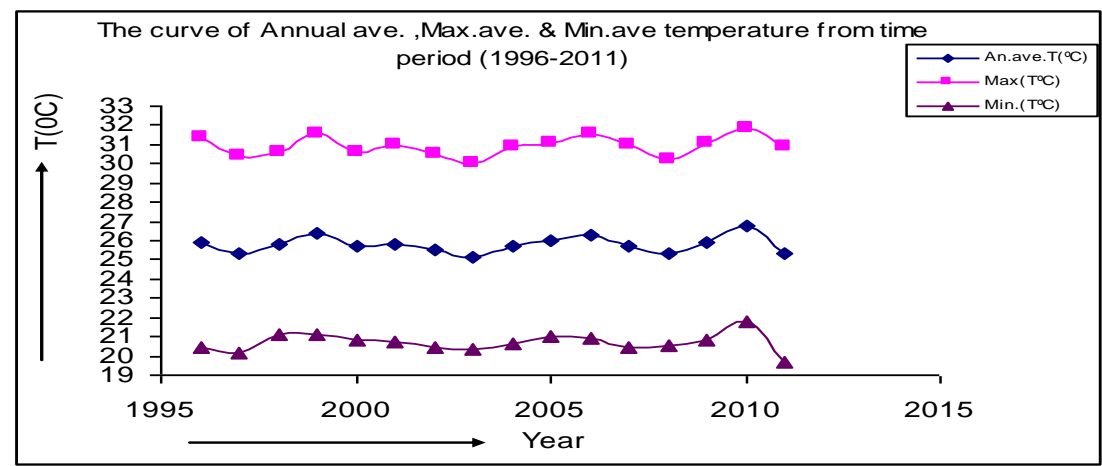

Fig.3 Representation of the annual average, annual average maximum and minimum

\subsection{Rainfall}

The single most dominant element of the climate of Bangladesh is the rainfall. Because of the country's location in the tropical monsoon region, the amount of rainfall is very high. However, there is a distinct seasonal pattern in the annual cycle of rainfall, which is much more pronounced than the annual cycle of temperature. The winter season is very dry, and accounts for only $2 \%-4 \%$ of the total annual rainfall.

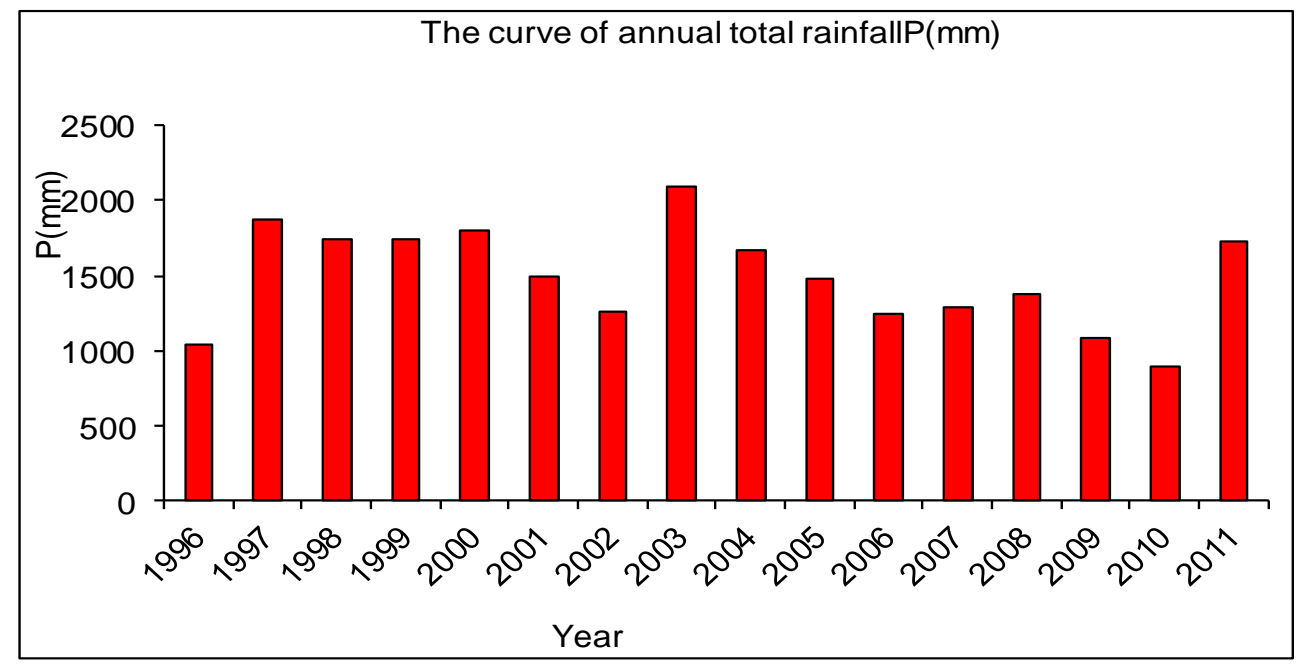

Fig.4 Distribution of annual total rainfall of the different years (1996-2011)

Rainfall during this season varies from less than $2 \mathrm{~cm}$ in the west and south to slightly over $4 \mathrm{~cm}$ in the northeast. The amount is slightly enhanced in the north eastern part due to the additional uplifting of moisture provided by the Meghalaya Plateau. As the winter season progresses into the pre-monsoon hot season, rainfall increases due to intense surface heat and the influx of moisture from the Bay of Bengal. Rainfall during this season accounts for $10 \%-25 \%$ of the total annual rainfall, which is caused by the thunderstorms or locally called Kalbaishakhi. The average annual rainfall of $2860 \mathrm{~mm}$ (122 inches) clearly indicates that Bangladesh rightly qualifies to be a country of heavy rainfall. The bulk of the rain, however, falls in the rainy months of June to September (Khan, 1991).The area receives a high amount of rainfall with an annual average of 1488.85 $\mathrm{mm}$ in the Ishurdi Pabna from time period (1996-2011). There is a large variation in the rainfall from year to year. As for example, rainfall recorded in 1996 was about $1044.5 \mathrm{~mm}$, but in 2011 it was $1723.5 \mathrm{~mm}$. Distribution of annual total rainfall of the different years (1996-2011) is shown in Fig. 4. There are three main sources of rainfall in the region: (1) the western depression of winter, (2) the early summer thunderstorm; and the summer rain known as monsoon (Rashid, 1979). The mean monthly rainfall in the region follows a pattern. Generally, a maximum rainfall $311.6331 \mathrm{~mm} / \mathrm{month}$ is observed in the month of July and a minimum of 5.60 $\mathrm{mm} / \mathrm{month}$ in the month of December. The other months of the year observe a gradual increase of rainfall from the minimum to maximum or vice versa. 


\section{Conclusion}

The temperature and rainfall of the Ishurdi Pabna are averaged to get the time series of mean temperature and annual rainfall. The annual average, annual average maximum and minimum temperature from time period (1996-2011) in the study area is shown in fig 3. The annual rainfall from time period (1996-2011) is shown in fig 4 . The De Martonne Aridity Index define the class of aridity named moist sub-humid and the precipitation supports dense growth of tall or short grasses, but not forests is called the sub-humid. The moist sub-humid zone is defined as the periods up to 90 days when soil moist sub-humid significant moisture deficit during growing season $(6.4-12.0 \mathrm{~cm})$ XERIC Soil dry 45 of 120 consecutive days after winter/summer solstice. On the other hand, the climate of Bangladesh is mostly humid type. The northeastern side of the country belongs to wet climate and the central western part of the country belongs to moist sub-humid climate. Low rainfall and high variation between winter and summer temperature is the characteristics of moist sub-humid zone of Bangladesh. Mean annual rainfall in this zone is less than $2000 \mathrm{~mm}$ and the mean temperature varies between $20^{\circ} \mathrm{C}$ in winter and $32^{\circ} \mathrm{C}$ in summer. In summer, some of the hottest days experience a temperature of about $45^{\circ} \mathrm{C}$ or even more and in winter it falls to about $5^{\circ} \mathrm{C}$ in some places of this zone (Banglapedia, 2003). But in summer, some of the hottest days experience a temperature of about $36.8^{\circ} \mathrm{C}$ or even more and in winter it falls to about $8.1^{\circ} \mathrm{C}$ in the Ishurdi Pabna from time period 1996-2011. The study reveals that Ishurdi Pabna required irrigation for Pre, post and winter monsoon period. The monthly analysis of data reveals that dry months are concentrated mainly in post monsoon and pre-monsoon period. The study reveals that the trend of the seasonal average monthly aridity index has been decreased for the pre-monsoon is $-0.8702 \%$, post monsoon $-0.4234 \%$ and winter monsoon $-0.0224 \%$ at level of $95 \%$ level confidence shown in fig 1 and fig 2 .The significant increase of rainfall in Ishurdi Pabna has no impact on the time-span of irrigation demand periods. This may be due to the increase of temperature and no change of rainfall during dry months in this region.

\section{References}

[1]. Banglapedia National Encyclopedia of Bangladesh. Dhaka, Asiatic Society of Bangladesh (2003).

[2]. Shahid S. Spatial and Temporal Characteristics of Droughts in the Western Part of Bangladesh, Hydrological Processes, 2008, Vol. 22(13), 2235-2247

[3]. Shahid, S. and Behrawan, H. Drought Risk Assessment in the Western Part of Bangladesh, Natural Hazards 2008, Vol.46 (3), 391 413.

[4]. Gregory, S. Statistical Methods and the Geographer, 1978 New York: Longman.

[5]. Lanzante, J.R. Resistant, robust and non-parametric techniques for the analysis of climate data: theory and examples including applications to historical radio station data, 1996 International Journal of Climatology, Vol.16, 1197-1226.

[6]. De Luis, M., Raventos, J., Gonzalez-Hidalgo, J.C., Sanchez, J.R., and Cortina, J. Spatial Analysis of Rainfall Trends in the Region of Valencia (East Spain), Internal Journal of Climatology, 2000 Vol. 20, 1451-1469.

[7]. Isaaks, H.E., and Srivastava, R.M. An Introduction to Applied Geostatisitics, 1989 New York, Oxford University Press

[8]. Rashid, H.E. Geography of Bangladesh, Dhaka: University Press Ltd. 1991.

[9]. Study of the Agricultural Status of The Western Barind Tract, Northwest Bangladesh Using Remote Sensing and GIS Technology, SPARRSO Annual Report, September1996, p.17

[10]. Yu, B., and Neil, D.T. Long-term variations in regional rainfall in the south-west of Western Australia and the difference between average and high intensity rainfalls, International Journal of Climatology, 1993 Vol. 13, 77-88.

[11]. Md. Nazrul Islam, Rainfall and Temperature Scenario for Bangladesh, the Open- Atmospheric Science Journal, 2009, Vol. 3, 93103. 